\title{
Visceral obesity and chronic pain: effect of a 4-week rehabilitation program on adipokines and insulin resistance
}

\author{
Florence Doury-Panchout ${ }^{1, *}$, Jean-Charles Metivier ${ }^{2}$, Julien Nardoux ${ }^{1,2}$, Bernard Fouquet ${ }^{3}$ \\ ${ }^{1} \mathrm{CHU}$ Tours, Service de Médecine Physique et Réadaptation, Tours, France \\ ${ }^{2}$ CHIC Amboise Château-Renault, Service de Médecine Physique et Réadaptation, Hôpital « Docteur Jean Delaneau » Rue Jules Joran, Château Renault, France \\ ${ }^{3}$ Fédération Universitaire Inter-Hospitalière de Médecine Physique et Réadaptation, CHU Tours, Tours, France
}

Obesity and chronic pain are two major diseases of the 21th century. Our principal objective was to investigate the effects of a 4-week rehabilitation program on adiponectin and leptin concentrations, and insulin resistance, in patients with abdominal obesity and chronic pain syndrome. Our secondary objectives were to investigate the effects of this program on pain, body mass index (BMI), waist circumference and maximal oxygen consumption $\left(\mathrm{VO}_{2 \text { max }}\right)$ and to compare changes in $\mathrm{VO}_{2 \mathrm{~m}-}$ ax between patients with or without insulin resistance. Among a consecutive sample of 128 patients with abdominal obesity hospitalized for rehabilitation for a chronic pain syndrome, 111 completed the protocol, which was a 4-week rehabilitation program including $6 \mathrm{hr}$ of rehabilitation per day, 5 days per week, in a referral center of rehabilitation. This prospective cohort study compared clinical (BMI, waist circumference, $\mathrm{VO}_{2 \max }$, pain) and biological measures (concentrations of adiponectin, leptin and insulin, score of homeostasis model assessment of insulin resistance [HOMA]) before and after the program. Plasma leptin, adiponectin and insulin concentrations $(P<0.0001)$ and score of HOMA $(P=0.0002)$ had decreased significantly by the end of the 4 weeks. Pain, $\mathrm{BMI}$ and waist circumference decreased significantly, and $\mathrm{VO}_{2 \max }$ improved significantly $(P=0.0001)$. Patients with insulin resistance had less improvement of their aerobic condition at the end of the 4 weeks $(P<0.002)$. The rehabilitation program decreases the concentration of leptin, and improves insulin sensitivity in patients with chronic pain and visceral obesity. Aerobic recovery was worse for patients with insulin resistance than other patients.

Keywords: Exercise, Obesity, Adipokines, Oxygen consumption, Pain

\section{INTRODUCTION}

Obesity and chronic pain are two major diseases of the 21th century. Epidemiological studies show that the body mass index (BMI) of the general population has been increasing since 1990 (De Saint Pol, 2008). Our understanding of the pathophysiology of obesity has been improving, and it is now clear that the complications of obesity can be classified into two main groups (Ciangura and Poitou-Bernet, 2011): (a) mechanical and hemodynamic factors: high articular load, poor pulmonary compliance, abdominal hyperpression, higher than normal cardiac output; (b) biological factors: adipokines, functional hypercortisolism, insulin resis- tance and inflammatory syndrome.

Because of the complexity of this disease, the medical care of obesity needs to be multidisciplinary, and to include physical activity, improved diet, and psychological support (Ghroubi et al., 2009). This approach leads to weight loss (Garrow and Summerbell, 1994; Ghroubi et al., 2009), reduction of cardiovascular risk factors (Ghroubi et al., 2009; Fagard, 1999; Kelley et al., 2001), reduction of metabolic disorders (Kelley et al., 2005) and reduction of psychological and functional problems (Ghroubi et al., 2009; Maciejewski et al., 2005). Furthermore, musculoskeletal pain is more common in obese patients (Viester et al., 2013). It's usual to propose rehabilitation program to patients with chronic
${ }^{*}$ Corresponding author: Florence Doury-Panchout

(iD) https://orcid.org/0000-0003-3735-4876

Department of Physical Medicine and Rehabilitation, University Hospital of Tours, 37044 Tours Cedex 9, France

Tel: +33-247474677, Fax: +33-247477299, E-mail: florence.dourypanchout@gmail.com Received: February 1, 2017 / Accepted: July 17, 2017
This is an Open Access article distributed under the terms of the Creative Commons Attribution Non-Commercial License (http://creativecommons.org/licenses/by-nc/4.0/) which permits unrestricted non-commercial use, distribution, and reproduction in any medium, provided the original work is properly cited. 
pain syndrome, especially when a long duration of work incapacity is associated (Poiraudeau et al., 2007). In the rehabilitation center of the hospital of Château-Renault, we are used to take care of obese patients with chronic pain syndrome (low back pain, nonspecific musculoskeletal pain of the upper limb, or diffuse chronic pain syndrome). So, we asked whether our rehabilitation program improves metabolic complications of obesity, in these patients with chronic pain syndrom. In the general population, physical activity reduces cardiovascular risk, helps prevent diabetes, neoplasia, hypertension, depression and osteoporosis, and reduces the risk of early mortality (Katzmarzyk and Lear, 2012). There are numerous studies on the effect of exercise interventions on metabolic changes in obese patients, and most of them found that physical activity had small effects on cholesterol disorders, insulin concentrations or inflammatory syndrome in obese populations, but did not conclude about whether physical activity had an independent effect (Golbidi and Laher, 2014; Katzmarzyk and Lear, 2012). There is no study about the effect of exercise intervention on metabolic changes in obese patients with chronic pain syndrome.

Our hypothesis was: rehabilitation program by obese patients with chronic pain syndrome leads to an improvement of the adipokine profile (decrease of leptin and increase of adiponectin concentrations), a reduction of insulin resistance and an improvement of aerobic capacity.

Our main aim was to evaluate changes in plasma concentrations of leptin, adiponectin, and insulin concentration after a 4-week rehabilitation program. Our secondary objectives were:

- to evaluate changes in maximal oxygen consumption $\left(\mathrm{VO}_{2 \max }\right)$, weight, BMI, and waist circumference, pain

- to investigate correlations between the changes in the various clinical and biological measures

- to compare changes in $\mathrm{VO}_{2 \max }$ between patients with or without insulin resistance.

\section{MATERIALS AND METHODS}

\section{Design}

The design of research was a cohort study.

\section{Population}

All patients with abdominal obesity (i.e., waist circumference $>88 \mathrm{~cm}$ for women and $102 \mathrm{~cm}$ for men) hospitalized for rehabilitation for a chronic pain syndrome in the Physical Medicine and Rehabilitation unit of the Château-Renault hospital between 1st February 2011 and 31st May 2012 were included in the study.
These patients were referred by general practitioner, rheumatologist, or orthopedist surgeon to the unit of physical medicine and rehabilitation (PMR), and had a consultation before hospitalization to confirm the indication of a rehabilitation program or to exclude patient in case of contraindication. The inclusion criteria were: waist circumference $\geq 88 \mathrm{~cm}$ for women and $102 \mathrm{~cm}$ for men, age between 18 and 60 years, rehabilitation for chronic pain syndrome (low back pain, nonspecific pain of upper limb, or diffuse chronic pain syndrome). No patient was excluded, according to the criteria for admission to the unit. All participants gave written informed consent to the referent doctor of PMR unit. Data were processed in conformity with the recommendations of the CNIL (the French Commission for Information Technology and Civil Liberties). The study involved no changes to the assessments routinely performed in the unit.

\section{Methods}

All subjects underwent the same initial and final assessment in the unit (at the start of hospitalization, and at the end of the 4-week rehabilitation program). The data collected were:

- Weight, height, and BMI calculation

- Waist circumference

- Glycemia on an empty stomach

- Radio-immunological measure of leptin and adiponectin concentrations in blood (by the Laboratory of Nuclear Medicine of the University Hospital of Tours)

- Radio-immunological measure of insulin concentration (by the Laboratory of Biochemistry of the University Hospital of Tours).

- Calculation of homeostasis model assessment of insulin resistance (HOMA).

- Highest value of $\mathrm{VO}_{2}$ and maximal power collected during a cycloergometer exercise test with $\mathrm{VO}_{2 \max }$ measurement. The test was progressive starting at $30 \mathrm{~W}$ and increasing in $30-\mathrm{W}$ increments lasting $3 \mathrm{~min}$ each, until failure, using a Cardio-control Ergometer (ELMED, Augsburg, Germany), and $\mathrm{VO}_{2 \max }$ measurement using a MedGraphics Cardiorespiratory Diagnostic System (Cardio-MedGraphics Cardiorespiratory Diagnostic System GmbH, Braunsfels, Germany) gas exchange analyser.

- Evaluation of pain by analogic visual scale (AVS)

- All patients underwent a 4-week rehabilitation program, including $6 \mathrm{hr}$ of rehabilitation per day, 5 days per week, involving - Six muscular strengthening exercises individually created using one-repetition maximum (1RM), with a progressive in- 
crease of the difficulty ( $50 \%$ of $1 \mathrm{RM}$ the 2 first weeks, $75 \%$ the third week and $100 \%$ the last week)

$\cdot 1 \mathrm{hr}$ of aerobic training: with monitoring of pulse between $60 \%$ and $80 \%$ of maximal theoretical heart rate, which is calculated with the equation: 220-age

.1 hr of stretching

.30 to 45 min of occupational therapy

. One appointment with a dietetician who gives some advices to patients. Patients had a normocaloric diet during hospitalization.

The objectives of this rehabilitation are to improve aerobic capacities, strength, flexibility, and management of pain, and to help patients return to work. We compared patient characteristics before and after rehabilitation.

\section{Subgroup analysis}

We compared changes in aerobic capacities between patients with or without insulin resistance.

\section{Statistical analysis}

Student $t$-tests were used for comparisons of quantitative values for populations of more than 30 patients (mean values of adipokines and insulin concentrations before and after rehabilitation, mean values of $\mathrm{VO}_{2 \max }$, maximal power before and after rehabilitation, and mean values of pain and anthropometric measures before and after rehabilitation), and Wilcoxon tests were used for populations of less than 30 patients (comparison between patients with or with-

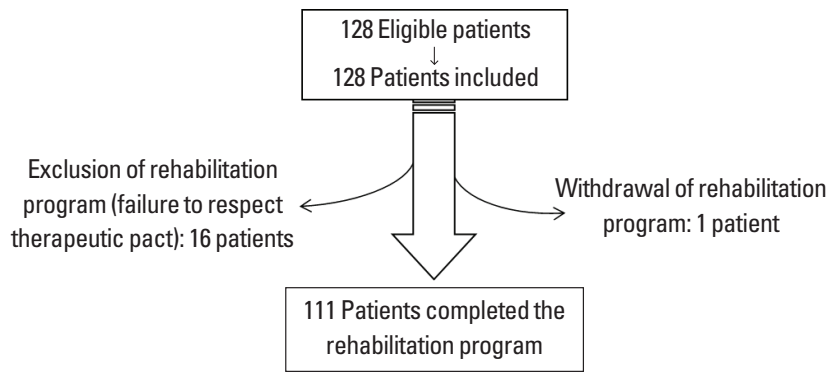

Fig. 1. Flow diagram.

Table 1. Changes in adipokine and insulin concentrations and HOMA score

\begin{tabular}{lccc}
\hline Variable & Before rehabilitation & After rehabilitation & $P$-value \\
\hline Leptin $(\mathrm{ng} / \mathrm{mL})$ & $25.6 \pm 19.1$ & $17.7 \pm 14.4$ & 0.0001 \\
Adiponectin $(\mu \mathrm{g} / \mathrm{mL})$ & $10.3 \pm 9.3$ & $8.3 \pm 7.3$ & 0.0001 \\
Insulin $(\mathrm{pmol} / \mathrm{L})$ & $59.7 \pm 32.1$ & $49.1 \pm 27.4$ & 0.0001 \\
HOMA score & $1.9 \pm 1.2$ & $1.6 \pm 0.9$ & 0.0002 \\
\hline
\end{tabular}

Values are presented as mean \pm standard deviation.

HOMA, homeostasis model assessment of insulin resistance. out insulin resistance). Correlations between the variations of quantitative measures were studied using a Statview correlation test. A difference was considered to be statistically significant if $P<0.05$.

Data for the patients excluded from the study (those not completing the protocol) were not included in the analyses.

\section{RESULTS}

\section{Population}

Of the 128 patients initially assessed, 111 ( 41 men, 70 women) completed the study protocol (mean age, 43.3 years; mean BMI, $31.2 \mathrm{~kg} / \mathrm{m}^{2}$; mean duration of sick leave, 11.6 months; mean weight gain during sick leave, $6.8 \mathrm{~kg}$; mean pain measured by AVS, $50.47 \mathrm{~mm}$ ) (Fig. 1).

\section{Adipokines and insulin resistance}

Leptin, adiponectin, and insulin concentrations $(P<0.0001)$ were all significantly lower and the HOMA score was lower $(P=0.0002)$ after than before the rehabilitation program (Table 1). At the start of the program, 28 patients had insulin resistance (HOMA score > 2.4) versus 19 patients at the end of the program (Table 2). There was a significant correlation between leptin and adiponectin changes $(r=0.22, P<0.03)$. There was no correlation between the other biological endpoints.

\section{Clinical endpoints}

Both BMI $(P=0.0001)$ and waist circumference $(P=0.0001)$ were significantly lower after than before the 4 -week rehabilita-

Table 2. Change in the proportion of patients with insulin resistance

\begin{tabular}{|c|c|c|c|}
\hline & \multicolumn{3}{|c|}{ HOMA before rehabilitation (insulin resistance) } \\
\hline & $\leq 2.4$ & $>2.4$ & Total \\
\hline \multicolumn{4}{|c|}{$\begin{array}{l}\text { HOMA after rehabilitation } \\
\text { (insulin resistance) }\end{array}$} \\
\hline$\leq 2.4$ & $77(83.3)$ & $15(16.7)$ & $92(82.6)$ \\
\hline$>2.4$ & $6(31.6)$ & $13(68.4)$ & $19(17.4)$ \\
\hline Total & $83(74.3)$ & $28(25.7)$ & $111(100)$ \\
\hline
\end{tabular}

Values are presented as number (\%).

Table 3. Change in clinical endpoint values

\begin{tabular}{lccc}
\hline Variable & Before rehabilitation & After rehabilitation & $P$-value \\
\hline BMI $\left(\mathrm{kg} / \mathrm{m}^{2}\right)$ & $31.1 \pm 4.9$ & $30.6 \pm 4.7$ & 0.0001 \\
Waist circumference $(\mathrm{cm})$ & $104.8 \pm 10.9$ & $101.4 \pm 10.4$ & 0.0001 \\
Pain (AVS, $\mathrm{mm})$ & $50.47 \pm 19.7$ & $19.01 \pm 18.67$ & 0.0001
\end{tabular}

Values are presented as mean \pm standard deviation BMI, body mass index; AVS, analogic visual scale. 
Table 4. Change in aerobic capacities

\begin{tabular}{lccc}
\hline Variable & Before rehabilitation & After rehabilitation & $P$-value \\
\hline $\mathrm{VO}_{2} \mathrm{max}(\mathrm{mL} / \mathrm{kg} / \mathrm{min})$ & $21.2 \pm 4.9$ & $24.3 \pm 5.4$ & 0.0001 \\
Maximal power $(\mathrm{W})$ & $138.9 \pm 36.2$ & $163.1 \pm 41.2$ & 0.0001 \\
Maximal heart rate $(\% \mathrm{TMHR})$ & $93.7 \pm 7.6$ & $93.8 \pm 7.2$ & $\mathrm{NS}$ \\
\hline
\end{tabular}

Values are presented as mean \pm standard deviation.

$\mathrm{VO}_{2 \text { max }}$, maximal oxygen consumption; NS, not significant; TMHR, theoretical maximal heart rate (TMHR=220-age).

tion program (Table 3). Both $\mathrm{VO}_{2 \max }(P=0.0001)$ and maximal power $(P=0.0001)$ were significantly increased (Table 4$)$. There was no correlation between the changes in clinical and biological endpoints. There was no correlation between the changes in pain and the changes in BMI or waist circumference (Table 5).

Pain was significantly decreased after the 4-week rehabilitation program $(P=0.0001)$. There was no correlation between the changes in pain and biological endpoints (Table 5).

\section{Subgroups analysis}

We noted a significant difference in the $\mathrm{VO}_{2 \max }$ change between patients with or without insulin resistance: the mean increase of $\mathrm{VO}_{2 \max }$ was $3.48 \mathrm{~mL} / \mathrm{kg} / \mathrm{min}$ in patients without insulin resistance $(\mathrm{n}=83)$ versus $0.65 \mathrm{~mL} / \mathrm{kg} / \mathrm{min}$ for patients with insulin resistance $(\mathrm{n}=28)(P<0.002)$, independently of weight differences between the two groups.

\section{DISCUSSION}

\section{Key results}

We found that a 4-week rehabilitation program significantly decreased circulating leptin and insulin concentrations in obese patients with chronic pain syndrome, i.e., that the program improved metabolic disorders associated with obesity. However, circulating adiponectin concentrations also decreased. There were significant decreases of pain, BMI, and waist circumference, and a significant improvement of aerobic capacity after the rehabilitation program.

\section{Study limitations}

Most of the patients included had a BMI $<35 \mathrm{~kg} / \mathrm{m}^{2}$, so our study is mostly uninformative about morbidly obese patients.

Our study has several technical limitations: we determined total adiponectin concentration, and did not consider the different isoforms and their relative abundance. We estimated insulin resistance using the HOMA score, which is better than the insulin concentration alone, but inferior to euglycemic clamping or intra-
Table 5. Correlations between changes in pain and changes in other endpoints

\begin{tabular}{lcc}
\hline Variable & $r$ & $P$-value \\
\hline$\Delta$ Leptin & 0.15 & 0.133 \\
$\Delta$ Adiponectin & 0.03 & 0.979 \\
$\Delta H O M A$ score & 0.02 & 0.846 \\
$\Delta \mathrm{VO}_{2 \max }$ & 0.04 & 0.996 \\
$\Delta \mathrm{BMl}$ & 0.05 & 0.573 \\
$\Delta$ Waist circumference & 0.11 & 0.274 \\
\hline
\end{tabular}

HOMA, homeostasis model assessment of insulin resistance; $\mathrm{VO}_{2 \max }$, maximal oxygen consumption; BMl, body mass index.

venous glucose tolerance tests (Raynaud et al., 1998).

Finally, our study considered the effects of physical activity immediately after the rehabilitation program, but does not provide any information about subsequent or long-term effects of the rehabilitation program on adipokine concentrations and insulin resistance.

\section{Interpretation}

\section{Effects on leptin concentration}

The effect of physical activity on leptin concentrations has been studied in both trained or sedentary subjects, and results depend on age, sex, characteristics of population and training (intensity, duration, and modality for example), but most studies on obese people conclude that physical activity decrease leptin concentrations (Bonora et al., 2002; De Luis et al., 2008; Golbidi and Laher, 2014; Loria-Kohen et al., 2013; Zaccaria et al., 2013). Changes in leptin concentrations after short periods of training (less than 12 weeks) seem to be modulated by various factors. These factors include initial metabolic status: physical activity decreases leptin concentrations especially in diabetic patients (Barwell et al., 2008). De Luis et al. (2008) suggest that weight loss mat contribute to explaining the decrease of leptin concentrations after training. Modalities of training and energy expenditure also plays a role in the variation of leptin concentrations (Zaccaria et al., 2013). However, in our study, we did not find any correlation between changes in leptin concentration and weight loss.

\section{Effects on adiponectin concentration and insulin sensitivity}

Many studies involving various training protocols (different intensities, durations, and types of exercises) and populations have found an improvement of insulin sensitivity after physical activity (Boudou et al., 2003; Christiansen et al., 2010; Hulver et al., 2002; Kriketos et al., 2004; Lim et al., 2008). Several mechanisms have been proposed to explain this effect: increased intracellular insulin signaling (Dela et al., 1993), increased glucose-bind- 
ing protein availability (Dela et al., 1994), increased glycogenesis enzyme activity and hexokinases activity (Ebeling et al., 1993), decreased release and increased clearance of free fatty acids (Ivy et al., 1999), increased glucose distribution to muscle, and modification of muscle composition (Andersson et al., 1998).

Several studies addressed the changes in adiponectin concentrations after physical activity, and the results reported are divergent: some studies found no change in adiponectin concentrations after training (Ando et al., 2009; Boudou et al., 2003; Coker et al., 2009; Hulver et al., 2002; Yokoyama et al., 2004), whereas some found increases and others decreases of adiponectin concentrations (Christiansen et al., 2010; Kriketos et al., 2004; Lim et al., 2008; Oberbach et al., 2006; Rokling-Andersen et al., 2007). Most of the authors agree that there is no correlation between changes in adiponectin concentration and insulin sensitivity; this strongly suggests that the improvement in insulin sensitivity associated with physical activity does not depend on changes in adiponectin concentration. Note however that most of these studies (including ours) considered only the overall total adiponectin concentration, without individualizing values for the several different isoforms. Recent studies in mouse and humans (Fisher et al., 2005; Pajvani et al., 2004) suggest that the proportions of high molecular weight and low molecular weight adiponectin are more relevant than overall adiponectin concentration alone to determining insulin sensitivity. A few studies, with small sample sizes, looked for the effects of physical activity on high molecular weight adiponectin concentration, but did not find any such effect (Guo et al., 2011; Magkos et al., 2010; Numao et al., 2011).

We also found that the improvement of aerobic capacity was smaller for patients with insulin resistance than patients without insulin resistance. Presumably, skeletal muscle metabolic disorders and abnormalities of fat metabolism, usually found in patients with insulin resistance, impede the improvement of aerobic capacity during the rehabilitation program, such that it is slower than patients without metabolic abnormalities. Skeletal muscle contains less type I oxidative fibers and more type II fibers (less sensitive to insulin) in patients with type 2 diabetes and in obese patients than in normal healthy subjects, (Holmäng et al., 1993; Pérez-Martin et al., 2001). Moreover, insulin resistance is responsible for glycogen storage disorders and abnormal glucose use by skeletal muscle (Damsbo et al., 1991; Golay and Felber, 1994; Pérez-Martin et al., 2001). The oxidative pathway is also impaired in patients with insulin resistance: creatine kinase activity and glycolytic capacity are abnormally high in skeletal muscle, leading to an increase of anaerobic metabolism (Simoneau et al., 1995). In obese patients, insulin resistance correlates with high

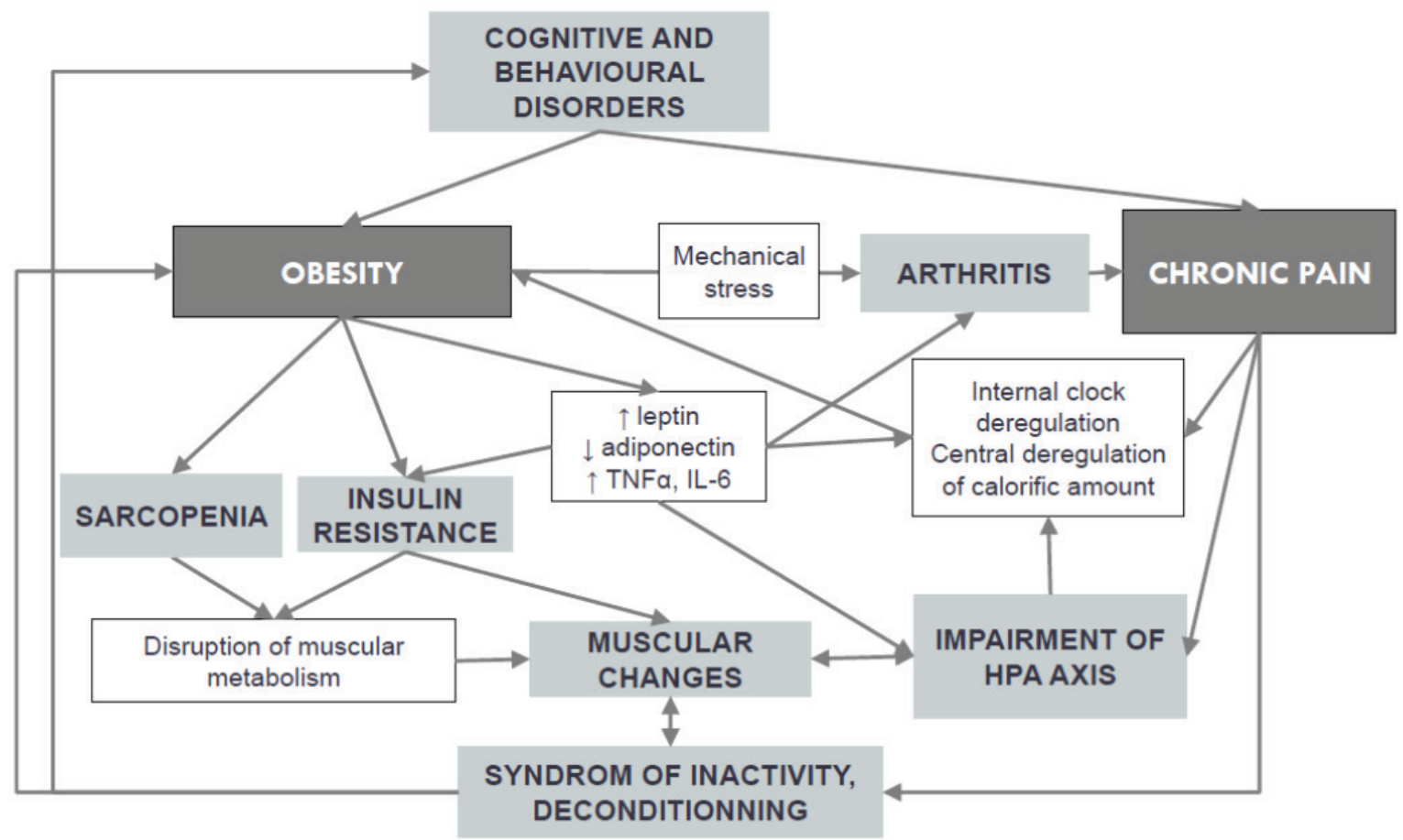

Fig. 2. Pathways between chronic pain and obesity. TNF, tumor necrosis factor; IL, interleukin; HPA axis, hypothalamic-pituitary-adrenal axis. 
glycolytic activity and low activity of oxidative enzymes, including pyruvate dehydrogenase (Simoneau et al., 1995); also, the oxidative capacity of lipids is low (Pérez-Martin et al., 2001; Ranneries et al., 1998), although the mechanism is unknown. All these observations contribute to the explanation of the poor recovery of aerobic capacity in patients with insulin resistance. Further studies are needed to explore this finding. In particular, it would be useful to determine whether patients with insulin resistance need a longer rehabilitation programs to recover sufficient aerobic capacity and correct aerobic deconditioning, which exists in patients with chronic pain syndromes.

\section{Chronic pain and obesity: what about clinical impacts?}

Numerous pathways exist between chronic pain and obesity (Fig. 2). Obesity is known to be a risk factor to develop musculoskeletal pain (Viester et al., 2013), and deconditioning syndrome in patient with chronic pain often results in behavioral changes which contributes to weight gain. Moreover, obesity (by insulin resistance) and chronic pain (by deconditioning) results in changes in metabolism of muscles. Some links have been found between osteoarthritis, pain and adipokines (Bas et al., 2014; Perruccio et al., 2014). Some authors found impairment of hypothalamic-pituitary-adrenal axis in patients with chronic pain (Aloisi et al., 2011; Tennant, 2015), which can contribute to weight gain.

Relations between obesity and chronic pain are very complicated, and it will be very difficult to prove whether exercise only can improve pain and/or metabolic changes linked to obesity. Yet, exercise can improve more of the pathways between obesity and chronic pain: insulin resistance, adipokine concentrations, metabolism of muscle, syndrome of inactivity, pain, cognitive and behavioral disorders, etc. To our mind, both medical care of obesity and chronic pain have to be multidisciplinary and must include physical exercise.

It's very difficult for these patients, who are obese and have chronic pain to reconnect with sports, and rehabilitation program is an interesting way.

\section{Clinical messages}

- Four weeks of rehabilitation decreases leptin concentration, insulin resistance, BMI, and improves aerobic capacities in patients with abdominal obesity and chronic pain syndrome.

- Patients with insulin resistance may need a longer rehabilitation program to recover sufficient aerobic capacity.

- Numerous pathways exist between obesity and chronic pain. A multidisciplinary approach is necessary and must include physical exercise.

\section{CONFLICT OF INTEREST}

No potential conflict of interest relevant to this article was reported.

\section{ACKNOWLEDGMENTS}

We wish to thank Professor C. Couet for his advices. We wish to thank the physiotherapists, physical trainers, occupational therapists, dietician and nurses in the physical medicine and rehabilitation department at Château-Renault general hospital for their help in performing the study

\section{REFERENCES}

Aloisi AM, Buonocore M, Merlo L, Galandra C, Sotgiu A, Bacchella L, Ungaretti M, Demartini L, Bonezzi C. Chronic pain therapy and hypothalamic-pituitary-adrenal axis impairment. Psychoneuroendocrinology 2011;36:1032-1039.

Andersson A, Sjödin A, Olsson R, Vessby B. Effects of physical exercise on phospholipid fatty acid composition in skeletal muscle. Am J Physiol 1998;274(3 Pt 1):E432-438.

Ando D, Hosaka Y, Suzuki K, Yamagata Z. Effects of exercise training on circulating high molecular weight adiponectin and adiponectin oligomer composition: a randomized controlled trial. J Atheroscler Thromb 2009;16:733-739.

Barwell ND, Malkova D, Moran CN, Cleland SJ, Packard CJ, Zammit VA, Gill JM. Exercise training has greater effects on insulin sensitivity in daughters of patients with type 2 diabetes than in women with no family history of diabetes. Diabetologia 2008;51:1912-1919.

Bas S, Finckh A, Puskas GJ, Suva D, Hoffmeyer P, Gabay C, Lübbeke A. Adipokines correlate with pain in lower limb osteoarthritis: different associations in hip and knee. Int Orthop 2014;38:2577-2583.

Bonora E, Formentini G, Calcaterra F, Lombardi S, Marini F, Zenari L, Saggiani F, Poli M, Perbellini S, Raffaelli A, Cacciatori V, Santi L, Targher G, Bonadonna R, Muggeo M. HOMA-estimated insulin resistance is an independent predictor of cardiovascular disease in type 2 diabetic subjects: prospective data from the Verona Diabetes Complications Study. Diabetes Care 2002;25:1135-1141.

Boudou P, Sobngwi E, Mauvais-Jarvis F, Vexiau P, Gautier JF. Absence of exercise-induced variations in adiponectin levels despite decreased abdominal adiposity and improved insulin sensitivity in type 2 diabetic men. Eur J Endocrinol 2003;149:421-424.

Christiansen T, Paulsen SK, Bruun JM, Pedersen SB, Richelsen B. Exercise training versus diet-induced weight-loss on metabolic risk factors and 
inflammatory markers in obese subjects: a 12-week randomized intervention study. Am J Physiol Endocrinol Metab 2010;298:E824-831.

Ciangura C, Poitou-Bernert C. Complications des obésités. In: EM Consulte, editor. Endocrinologie-nutrition. Paris: Elsevier-Masson SAS; 2011. p. 10-506-E-10.

Coker RH, Williams RH, Kortebein PM, Sullivan DH, Evans WJ. Influence of exercise intensity on abdominal fat and adiponectin in elderly adults. Metab Syndr Relat Disord 2009;7:363-368.

Damsbo P, Vaag A, Hother-Nielsen O, Beck-Nielsen H. Reduced glycogen synthase activity in skeletal muscle from obese patients with and without type 2 (non-insulin-dependent) diabetes mellitus. Diabetologia 1991;34:239-245.

De Luis DA, Aller R, Izaola O, Gonzalez Sagrado M, Conde R, Perez Castrillon JL. Effects of lifestyle modification on adipocytokine levels in obese patients. Eur Rev Med Pharmacol Sci 2008;12:33-39.

De Saint Pol T. Obésité et milieux sociaux en France: les inégalités augmentent. Bulletin Epid emiologique AFSSA 2008;20:175-179.

Dela F, Handberg A, Mikines KJ, Vinten J, Galbo H. GLUT 4 and insulin receptor binding and kinase activity in trained human muscle. J Physiol 1993;469:615-624.

Dela F, Ploug T, Handberg A, Petersen LN, Larsen JJ, Mikines KJ, Galbo $\mathrm{H}$. Physical training increases muscle GLUT4 protein and mRNA in patients with NIDDM. Diabetes 1994;43:862-865.

Ebeling P, Bourey R, Koranyi L, Tuominen JA, Groop LC, Henriksson J, Mueckler M, Sovijärvi A, Koivisto VA. Mechanism of enhanced insulin sensitivity in athletes. Increased blood flow, muscle glucose transport protein (GLUT-4) concentration, and glycogen synthase activity. J Clin Invest 1993;92:1623-1631.

Fagard RH. Physical activity in the prevention and treatment of hypertension in the obese. Med Sci Sports Exerc 1999:31(11 Suppl):S624-630.

Fisher FM, Trujillo ME, Hanif W, Barnett AH, McTernan PG, Scherer PE, Kumar S. Serum high molecular weight complex of adiponectin correlates better with glucose tolerance than total serum adiponectin in Indo-Asian males. Diabetologia 2005;48:1084-1087.

Garrow J, Summerbell C. Meta-analysis on the effect of exercise on the composition of weight loss. Int J Obes Relat Metab Disord 1994;18:516517.

Ghroubi S, Elleuch H, Chikh T, Kaffel N, Abid M, Elleuch MH. Physical training combined with dietary measures in the treatment of adult obesity. A comparison of two protocols. Ann Phys Rehabil Med 2009; 52:394-413.

Golay A, Felber JP. Evolution from obesity to diabetes. Diabete Metab 1994;20:3-14.

Golbidi S, Laher I. Exercise induced adipokine changes and the metabolic syndrome. J Diabetes Res 2014;2014:726861.
Guo W, Kawano H, Piao L, Itoh N, Node K, Sato T. Effects of aerobic exercise on lipid profiles and high molecular weight adiponectin in Japanese workers. Intern Med 2011;50:389-395.

Holmäng A, Brzezinska Z, Björntorp P. Effects of hyperinsulinemia on muscle fiber composition and capitalization in rats. Diabetes 1993;42: 1073-1081.

Hulver MW, Zheng D, Tanner CJ, Houmard JA, Kraus WE, Slentz CA, Sinha MK, Pories WJ, MacDonald KG, Dohm GL. Adiponectin is not altered with exercise training despite enhanced insulin action. Am J Physiol Endocrinol Metab 2002;283:E861-865.

Ivy JL, Zderic TW, Fogt DL. Prevention and treatment of non-insulin-dependent diabetes mellitus. Exerc Sport Sci Rev 1999;27:1-35.

Katzmarzyk PT, Lear SA. Physical activity for obese individuals: a systematic review of effects on chronic disease risk factors. Obes Rev 2012;13:95-105

Kelley GA, Kelley KA, Tran ZV. Aerobic exercise and resting blood pressure: a meta-analytic review of randomized, controlled trials. Prev Cardiol 2001;4:73-80.

Kelley GA, Kelley KS, Vu Tran Z. Aerobic exercise, lipids and lipoproteins in overweight and obese adults: a meta-analysis of randomized controlled trials. Int J Obes (Lond) 2005;29:881-893.

Kriketos AD, Gan SK, Poynten AM, Furler SM, Chisholm DJ, Campbell LV. Exercise increases adiponectin levels and insulin sensitivity in humans. Diabetes Care 2004;27:629-630.

Lim S, Choi SH, Jeong IK, Kim JH, Moon MK, Park KS, Lee HK, Kim YB, Jang HC. Insulin-sensitizing effects of exercise on adiponectin and retinol-binding protein- 4 concentrations in young and middle-aged women. J Clin Endocrinol Metab 2008;93:2263-2268.

Loria-Kohen V, Fernández-Fernández C, Bermejo LM, Morencos E, Romero-Moraleda B, Gómez-Candela C. Effect of different exercise modalities plus a hypocaloric diet on inflammation markers in overweight patients: a randomised trial. Clin Nutr 2013;32:511-518.

Maciejewski ML, Patrick DL, Williamson DF. A structured review of randomized controlled trials of weight loss showed little improvement in health-related quality of life. J Clin Epidemiol 2005;58:568-578.

Magkos F, Mohammed BS, Mittendorfer B. Enhanced insulin sensitivity after acute exercise is not associated with changes in high-molecular weight adiponectin concentration in plasma. Eur J Endocrinol 2010; 162:61-66.

Numao S, Katayama Y, Hayashi Y, Matsuo T, Tanaka K. Influence of acute aerobic exercise on adiponectin oligomer concentrations in middle-aged abdominally obese men. Metabolism 2011;60:186-194.

Oberbach A, Tönjes A, Klöting N, Fasshauer M, Kratzsch J, Busse MW, Paschke R, Stumvoll M, Blüher M. Effect of a 4 week physical training program on plasma concentrations of inflammatory markers in pa- 
tients with abnormal glucose tolerance. Eur J Endocrinol 2006;154:577585.

Pajvani UB, Hawkins M, Combs TP, Rajala MW, Doebber T, Berger JP, Wagner JA, Wu M, Knopps A, Xiang AH, Utzschneider KM, Kahn SE, Olefsky JM, Buchanan TA, Scherer PE. Complex distribution, not absolute amount of adiponectin, correlates with thiazolidinedione-mediated improvement in insulin sensitivity. J Biol Chem 2004;279:1215212162.

Pérez-Martin A, Raynaud E, Mercier J. Insulin resistance and associated metabolic abnormalities in muscle: effects of exercise. Obes Rev 2001;2:47-59.

Perruccio AV, Mahomed NN, Chandran V, Gandhi R. Plasma adipokine levels and their association with overall burden of painful joints among individuals with hip and knee osteoarthritis. J Rheumatol 2014; 41:334-337.

Poiraudeau S, Rannou F, Revel M. Functional restoration programs for low back pain: a systematic review. Ann Readapt Med Phys 2007;50: 425-429.

Ranneries C, Bülow J, Buemann B, Christensen NJ, Madsen J, Astrup A. Fat metabolism in formerly obese women. Am J Physiol 1998;274(1 Pt 1):E155-161.

Raynaud E, Brun JF, Pérez-Martin A, Fédou C, Mercier J. In vivo evaluation of insulin sensitivity and clinical applications. Ann Biol Clin (Par- is) $1998 ; 56: 407-416$.

Rokling-Andersen MH, Reseland JE, Veierød MB, Anderssen SA, Jacobs DR Jr, Urdal P, Jansson JO, Drevon CA. Effects of long-term exercise and diet intervention on plasma adipokine concentrations. Am J Clin Nutr 2007;86:1293-1301.

Simoneau JA, Colberg SR, Thaete FL, Kelley DE. Skeletal muscle glycolytic and oxidative enzyme capacities are determinants of insulin sensitivity and muscle composition in obese women. FASEB J 1995;9:273278.

Tennant F. Hormone abnormalities in patients with severe and chronic pain who fail standard treatments. Postgrad Med 2015;127:1-4.

Viester L, Verhagen EA, Oude Hengel KM, Koppes LL, van der Beek AJ, Bongers PM. The relation between body mass index and musculoskeletal symptoms in the working population. BMC Musculoskelet Disord 2013;14:238.

Yokoyama H, Emoto M, Araki T, Fujiwara S, Motoyama K, Morioka T, Koyama H, Shoji T, Okuno Y, Nishizawa Y. Effect of aerobic exercise on plasma adiponectin levels and insulin resistance in type 2 diabetes. Diabetes Care 2004;27:1756-1758.

Zaccaria M, Ermolao A, Brugin E, Bergamin M. Plasma leptin and energy expenditure during prolonged, moderate intensity, treadmill exercise. J Endocrinol Invest 2013;36:396-401. 